\title{
RELAÇÕES COM A MÚSICA EM DIVERSOS CONTEXTOS DE FORMAÇÃO: SIGNIFICAÇÕES E SENTIDO DE VIDA
}

\author{
Establishing relations with music in various training \\ contexts: significances and meaning in life
}

\author{
Maura PenNa \\ Universidade Federal da Paraíba \\ maurapenna@gmail.com \\ ANA LUIZ PINTO \\ Universidade Federal da Paraíba \\ analuizallmp@gmail.com \\ SUSIE SANTOS \\ Universidade Federal da Paraíba \\ susieguima@gmail.com
}

\begin{abstract}
Resumo: Este artigo apresenta um recorte de pesquisa em andamento, com caráter interdisciplinar, que tem como objetivo geral compreender as relações subjetivas estabelecidas com a música e sua significação na vida de sujeitos que exercem uma prática musical regular. Adotamos a metodologia de história de vida, com o uso de entrevistas narrativas, tendo coletado dados com doze alunos de cursos superiores de música. A análise busca, inicialmente, caracterizar o percurso de formação dos participantes, com base em estudos da área de educação musical. Em seguida, tomamos como referência interpretativa a teoria do sentido da vida de Viktor Frankl para discutir como os sujeitos constroem suas relações pessoais com a música. Mostramos como elas são significativas, fazendo parte dos projetos de vida e dos esforços de busca e realização de um sentido de vida. Concluímos que a maioria dos participantes vem realizando sentidos e propósitos através de suas atividades musicais.
\end{abstract}

Palavras-chave: Relações subjetivas com a música. Logoterapia. Formação musical.

\begin{abstract}
This paper presents an ongoing research with interdisciplinary character, whose general goal is to understand the subjective relations that are established with music as well as its meaning in the life of individuals who are engaged in a regular musical practice. This research is based on the History of Life methodology, through the application of narrative interviews, collecting data from twelve tertiary level music majors. The analysis initially seeks to characterize the participant's training path, based on studies in the field of music education. Then, we take Viktor Frankl's theory of the meaning in life as interpretative reference in order to discuss how each individual establishes his/her personal relations to music. We show how significant they are, as part of their project of life as well as to the efforts towards searching and achieving meaning in life. We conclude that most of the interviewees have been carrying out meanings and purposes through their musical activities.
\end{abstract}

Keywords: Subjective relations with music. Logotherapy. Musical training. 


\section{INTRODUÇÃO}

Por que as pessoas estudam/aprendem música? Aqui "estudar/aprender" tem um sentido amplo, pois, além de aulas particulares ou escolas de música, existem diferentes formas de aprendizagem musical, em contextos culturais diversos, nem todos escolares ou institucionais, e nem todos centrados na figura de um "professor", como indicam vários estudos da área de educação musical (como, p.ex., Wille 2005). Assim, Green (2012) analisa diversos modos informais de aprendizagem no campo da música popular, enquanto Corrêa (2000) investiga processos de autoaprendizagem musical. Já Kleber (2014) e Almeida (2005) discutem atividades educativas musicais nos espaços não formais das Organizações Não Governamentais e em projetos sociais. Por sua vez, Travassos (1999) analisa o papel das igrejas evangélicas.

Diante do interesse em compreender a relação entre esses diferentes contextos socioculturais e os percursos de estudo e formação individuais, e, mais ainda, a dimensão subjetiva das significações da relação pessoal com a música, o Grupo de Pesquisa Música, Cultura e Educação, da Universidade Federal da Paraíba (UFPB), vem desenvolvendo estudos sobre o tema.

Por vezes, o início da formação musical pode não ter sido fruto de uma escolha pessoal consciente, como quando os pais colocam os filhos pequenos para ter aulas de música independentemente de sua vontade expressa, ou simplesmente quando a música está envolvida em outras práticas sociais como em atividades religiosas -, que acabam por se constituir em espaços não formais ou informais de educação musical. No entanto, depois de certa idade, quando o indivíduo ganha autonomia, o estudar/aprender música passa a ser uma opção pessoal. Considerando esse momento de escolha individual, nosso interesse está na relação pessoal e subjetiva que cada um estabelece com a música, o modo como experiencia essa relação ao longo da sua "história de vida musical": Qual a significação da música em sua vida? Que tipo de relação diferentes pessoas constroem com a música? Uma relação "utilitária", sendo a música um ganha-pão ou um meio de projeção social? Ou a música constitui um sentido de vida?

$\mathrm{E}$ aqui nos referimos ao sentido de vida nos termos de Victor Frankl, como o conceito que embasa sua proposta da Logoterapia. O termo logos origina-se do grego, cuja acepção significa "sentido", relacionado à existência humana. Assim, a Logoterapia "concentra-se no sentido da existência humana, bem como na busca da pessoa por este sentido. Para a Logoterapia, a busca de sentido na vida da pessoa é a principal força motivadora no ser humano" (Frankl, 2014, p. 124). Outro conceito básico da Logoterapia é a vontade de sentido, que diz respeito ao "esforço mais básico do homem na direção de encontrar e realizar sentidos e propósitos" (Frankl, 2013, p. 50). Com base nesses aportes teóricos, nossa pesquisa visa compreender quando 
e como as pessoas encontram e realizam um sentido de vida através da música.

Deste modo, nossa pesquisa adota uma perspectiva interdisciplinar, no entrecruzamento da psicologia com a educação musical. Diversas temáticas são trabalhadas no campo específico da "psicologia da música" - criatividade, desenvolvimento e mensuração de habilidades musicais, atitudes, preferências e julgamentos em relação à música e sua estética -, como mapeado por Cox et al. (2012) em periódicos de associações internacionais. Ou, ainda, Magalhães (2016) analisa a produção científica (a partir da segunda metade do século XIX) que se desenvolveu em torno da interface psicologia e música, categorizando-a em três eixos: razão, psicotécnicas e subjetividade - destacando neste último eixo a influência da psicanálise e de outras teorias psicológicas que enfatizam o inconsciente.

No campo específico da cognição musical, importantes coletâneas produzidas no Brasil (como Ilari, 2006; Ilari; Araújo, 2009; Araújo; Ramos, 2015) abordam uma variedade de temáticas, da motivação ao desenvolvimento de habilidades e da aprendizagem musicais. No entanto, embora reconhecendo que "a prática, o ensino e a aprendizagem musical são atividades conduzidas por meio de fatores emocionais, cognitivos e subjetivos, bem como são influenciadas pelas situações e condições do contexto social" (Araújo, 2015, p. 47), a emoção e os sentimentos em música são abordados a partir da interpretação/performance musical ou relacionados à atividade de apreciação.

Em nossos levantamentos, não encontramos menção a pesquisas quanto à música como sentido de vida ou sua compreensão à luz de Viktor Frankl e sua Logoterapia, embora esta já seja explorada na área de educação (Damásio; Silva; Aquino, 2010; Miguez, 2014). O único trabalho que conhecemos que utiliza essa base teórica na pesquisa de questões da educação musical é a tese de doutorado de Aquino (2017), vinculada ao nosso grupo de pesquisa. Isto marca, portanto, o caráter inédito desta pesquisa tanto na área de educação musical quanto na área de psicologia.

\section{A LOGOTEORIA COMO UMA POSSIBILIDADE INTERPRETATIVA}

A Logoteoria ${ }^{1}$ - ou psicologia do sentido da vida - foi criada pelo médico psiquiatra e neurologista vienense Viktor Emil Frankl (1905-1997), professor da Universidade de Viena que, durante a Segunda Guerra Mundial, passou três anos em campos de concentração nazistas, incluindo Auschwitz. Após este período de confinamento, Frankl desenvolveu sua teoria a partir da própria experiência como prisioneiro, sobrevivente do holocausto, que, ao sair, descobriu que toda sua família havia sido dizimada (Frankl, 2010, p. 107-119).

\footnotetext{
${ }^{1}$ A teoria de Frankl é mais conhecida como Logoterapia nos campos da psicologia e da psicanálise. Entretanto, como não estamos utilizando os conceitos para fins terapêuticos, preferimos utilizar o termo Logoteoria.
} 
De acordo com Frankl (2013, p. 26), a Logoteoria é sustentada por três princípios básicos: a liberdade de vontade, a vontade de sentido e o sentido da vida. O fundamento antropológico que embasa a Logoteoria é a liberdade de vontade. Por meio desta, "o homem não é livre de suas contingências, mas, sim, livre para tomar uma atitude diante de quaisquer que sejam as condições que sejam apresentadas a ele", através da dimensão noética (ou espiritual). Este princípio opõe-se ao determinismo, posto que o homem é um ser livre e responsável pelas suas próprias decisões:

[...] o homem é capaz de distanciar-se não apenas de uma situação, mas de si mesmo. Ele é capaz de escolher uma atitude com respeito a si mesmo e, assim fazendo, consegue tomar posição, colocar-se diante de seus condicionamentos psíquicos e biológicos. [...] O que importa, logo, não são os condicionantes psicológicos, ou os instintos por si mesmos, mas, sim, a atitude que tomamos diante deles. É a capacidade de posicionar-se dessa maneira que faz de nós seres humanos. (Frankl, 2013, p. 26)

Já a vontade de sentido diz respeito ao esforço básico para encontrar e realizar sentidos e propósitos, ao interesse contínuo do homem pelo significado de sua vida (Frankl, 2013, p. 50). Independentemente da satisfação ou frustração de qualquer outra necessidade, o desejo de sentido orienta a relação do homem com os outros, com a vida e consigo mesmo, permitindo-lhe "descobrir a coerência interna de sua existência" (Dourado et al., 2010, p. 26-27).

O sentido de vida não é o mesmo para todas as pessoas. Cada uma deve responder às questões levantadas constantemente e durante toda a sua existência em situações e momentos diferentes. Para Frankl, em quaisquer circunstâncias, a vida nunca deixa de ter sentido, pressupondo-se que cada indivíduo possui um sentido na vida, bastando encontrá-lo e vivenciá-lo (Damásio, 2010, p. 30). Assim, "o sentido não pode ser dado arbitrariamente, mas deve ser encontrado responsavelmente [...], [deve] ser buscado conscientemente", sendo a consciência "a capacidade intuitiva do homem para encontrar o sentido de uma situação" (Frankl, 2013, p. 82).

Nesta direção, Dourado et al. (2010, p. 49) entendem que, “ainda que [o sentido de vida] se modifique dinamicamente, é coerente falar de projeto de vida", já que o sentido de vida precisa ser buscado no mundo, na relação com os outros, nas atividades cotidianas. Entendemos, portanto, que pode ser através da música que muitas pessoas encontram e realizam sentidos e propósitos através de diversas atividades - sejam de performance, de criação ou de ensino.

Assim, o foco desta pesquisa está no modo como as relações subjetivas com a música integram os projetos de vida dos sujeitos participantes. Portanto, analisamos seus depoimentos com base nos estudos da área de educação musical, quanto aos aspectos socioculturais dos diversos contextos 
de ensino-aprendizagem de sua formação. Para a análise das relações pessoais com a música, em especial seu papel nos projetos de vida, tomamos como base interpretativa a teoria do sentido de vida de Frankl.

\section{O ENCAMINHAMENTO DA PESQUISA ${ }^{2}$}

Nossa proposta de pesquisa diferencia-se na medida em que focaliza a relação pessoal com a música, buscando compreender significações, sentimentos e aspectos emocionais, além de outras dimensões da subjetividade $^{3}$. Assim, adotamos o seguinte problema de pesquisa: O que a música significa para cada pessoa que investe na prática musical, desenvolvendo-a sistematicamente, buscando aprimorá-la e adotando-a para sua formação e/ou atuação profissional?

Este texto apresenta um recorte da pesquisa em andamento Percursos de Estudo e Formação Musical: significações pessoais da relação com a música, que está sendo desenvolvida desde agosto de $2016^{4}$. Seu objetivo é conhecer a trajetória individual de relação com a música através de estudos e experiências diversas e, neste percurso, identificar as significações subjetivas que a música ganha em diferentes momentos de vida e/ou em distintos contextos de estudo/aprendizagem ou de atuação musical, buscando perceber como a música influi na realização de um sentido de vida.

Optamos por uma pesquisa qualitativa, sendo a coleta de dados baseada na metodologia da história de vida, através de entrevistas narrativas. Foram realizadas duas entrevistas. A primeira, de caráter narrativo, concentrou-se na história de vida musical de cada sujeito. Neste ponto, apoiamo-nos em Flick (2004, p. 109-117), que parte do ceticismo em relação à possibilidade de se "obter experiências subjetivas no esquema de perguntas e respostas das entrevistas tradicionais, mesmo se este for controlado de maneira flexível” ( $p$. 109). Este autor considera a narrativa capaz de expressar a experiência subjetiva, apontando o seu caráter autobiográfico, embora possa focalizar um aspecto ou momento específico da vida que interesse à pesquisa - no nosso caso, a história de vida musical. A questão norteadora para esta primeira entrevista narrativa era:

Por favor, conte a sua relação com a música ao longo de sua vida. Comece pela sua infância e seus primeiros contatos com a música - qualquer tipo de música. Conte progressivamente como a música fez parte de sua vida e como você se sentia em relação a ela. Então, fale sobre a música em sua vida em diferentes momentos e ambientes (em casa, na família, com

\footnotetext{
${ }^{2}$ Este projeto foi submetido ao CONEP através da Plataforma Brasil, sendo aprovado em 2016 sob o protocolo CAAE 56274916.7.0000.5188.

${ }^{3} \mathrm{O}$ texto de Doring (2016), embora com outros referenciais teóricos, também explora aspectos relativos à relação subjetiva com a música, mas a própria autora aponta que a pesquisa ainda está em fase preliminar. ${ }^{4} \mathrm{~A}$ coleta de dados foi realizada pelas bolsistas de iniciação científica (PIBIC/CNPQ/UFPB) Susie Santos e Ana Luiza Pinto.
} 
amigos, na igreja, na escola, etc.), como você começou a tocar ou a cantar, como começou a estudar música (sozinho, com professores ou em escolas) e como você chegou até esse momento atual de sua formação ou de atuação musical. Relate também como, durante todo esse percurso, você se sentia em relação à música e qual o papel dela em cada momento de sua vida. Você não precisa ter pressa, porque tudo que for importante para você nos interessa.

Num segundo momento, foi realizada uma entrevista um pouco mais estruturada - retomando pontos da narrativa anterior -, buscando esclarecer o papel da música para a vida do participante, enfatizando a sua significação subjetiva e emocional em determinados momentos de seu relato. Por exemplo:

Como você se sente atualmente (ou se sentia em determinado momento da história de vida) em relação à música (ou a determinada prática musical: tocar/cantar, ensinar, compor etc.)?

Por depender da narrativa original, o roteiro (flexivel) para esta segunda entrevista só podia ser preparado após a transcrição e a análise preliminar do relato obtido na primeira. Todas as entrevistas foram gravadas em áudio e transcritas, empregando-se a ortografia padrão, mas respeitando a construção das frases empregadas pelos participantes. Nos trechos dos depoimentos citados ao longo deste artigo, omitimos as terminações de gênero, a fim de manter o anonimato dos participantes ${ }^{5}$.

Neste artigo, apresentamos a análise do material coletado no período de agosto de 2016 a maio de 2017 com 12 sujeitos, alunos do bacharelado e da licenciatura em Música da UFPB, três homens e nove mulheres, com idades entre 19 e 34 anos. Como estudantes universitários de música, todos exerciam com regularidade e continuidade uma prática musical (incluindo performance instrumental ou vocal) e investiam a maior parte de seu tempo e de seus esforços à sua formação superior. Seis entrevistados dedicavam-se ao campo da música popular, e os demais ao piano ou instrumentos de orquestra.

\begin{tabular}{c|c|c|c}
\hline Sujeito & Curso & Instrumento & Idade \\
\hline Sujeito 1 & Bacharelado & $\begin{array}{c}\text { Flauta } \\
\text { transversal }\end{array}$ & 20 anos \\
\hline Sujeito 2 & Bacharelado & Piano & 34 anos \\
\hline Sujeito 3 & Bacharelado & Violino & 30 anos \\
\hline Sujeito 4 & Bacharelado & Violino & 20 anos \\
\hline Sujeito 5 & Bacharelado & Harpa & 22 anos \\
\hline Sujeito 6 & Bacharelado & Violino & 22 anos \\
\hline Sujeito 7 & Licenciatura & Canto popular & 19 anos \\
\hline Sujeito 8 & Licenciatura & Cavaquinho & 29 anos \\
\hline
\end{tabular}

\footnotetext{
${ }^{5}$ Todos os participantes assinaram um Termo de Consentimento Livre e Esclarecido/TCLE.
} 


\begin{tabular}{c|c|c|c}
\hline Sujeito 9 & Licenciatura & Guitarra & 29 anos \\
\hline Sujeito 10 & Licenciatura & Canto popular & 34 anos \\
\hline Sujeito 11 & Licenciatura & Bateria & 23 anos \\
\hline Sujeito 12 & Licenciatura & Canto popular & 23 anos \\
\hline
\end{tabular}

Quadro 1: Características dos sujeitos participantes.

Esta escolha levou em conta as diferenças nos processos e percursos de formação musical, que permitiu discutir também as diversas formas de aprendizado, suas relações com contextos socioculturais distintos e as áreas de atuação no mercado de trabalho.

\section{CONTEXTOS E PERCURSOS DE FORMAÇÃO MUSICAL}

A partir das narrativas dos entrevistados e com base em estudos da área de educação musical, buscamos, inicialmente, caracterizar e analisar o percurso de formação dos sujeitos participantes. De acordo com os relatos, o início da formação musical de cada um foi, de certa forma, induzido pela vontade dos pais, pelo prazer de participar das atividades religiosas ou por vontade própria. Segundo Queiroz (2017), as influências das pessoas ou ambientes durante o percurso de vida estão vinculadas ao que ela chama de "aprendizagem experiencial", pois são experiências transformadoras e reguladoras no processo educacional e pessoal ao longo da vida dos sujeitos. Neste sentido, a influência do ambiente familiar foi fundamental para a maioria dos entrevistados:

[...] eu já nasci em um berço musical, meu pai era músico, ele participava de um grupo de choro; meu irmão já atuava profissionalmente [...]. Meu pai é luthier, então eu sempre via instrumentos pela casa e sempre me interessei muito por tocar (S4-E1, 4/4/2017) ${ }^{6}$.

Desde criança, bem criança, lá em casa [...], sempre foi um hábito da minha família escutar muita música [...]. Meu pai e minha mãe não tocavam, não, mas eu tinha tios que tocavam, e eu convivia bastante com eles, sabe? E eu vejo que isso também foi uma grande influência para mim, ter essa convivência com eles (S9-E1, 27/9/2016).

Podemos observar que o convivio familiar em um ambiente musical cria o que se conhece por uma aprendizagem por familiarização (Penna, 2015, p. 41), que tem por base as vivências musicais cotidianas e que, de modo quase imperceptivel - Gomes (2011) trata como "as lógicas do invisivel" - influencia tanto o gosto quanto a prática musical ${ }^{7}$. E, de certo modo, pode direcionar as

\footnotetext{
${ }^{6} \mathrm{~A}$ indicação S4-E1, 4/4/2017 corresponde ao número do sujeito, ao número da entrevista e à data em que foi realizada. Todas as entrevistas serão assim indicadas. Para diferenciar as citações bibliográficas dos trechos citados dos relatos, estes serão apresentados em itálico.

${ }^{7}$ Neste mesmo sentido, Vieira (2004, p. 142) refere-se à naturalização da "herança musical" familiar.
} 
escolhas e as decisões a respeito do que fazer de suas vidas, desenvolvendo expectativas em relação aos outros e a si mesmo (Queiroz, 2017, p. 475).

Minha mãe sempre falava: "Todo mundo toca um instrumento
de sopro na família, menos tu". Aí meu pai tentou, colocou eu
para tocar bombardino [...], para tocar fagote $[\ldots]$, não deu
certo. E assim $[\ldots .$. foi criada uma imagem como se eu fosse a
ovelha negra da familia [...] (S1-E1,26/9/2016).

No início de sua formação, os entrevistados geralmente contaram com o apoio da família, que via essa atividade como um reforço na educação, "um resquício da educação humanística burguesa" - nos termos de Travassos (1999, p. 129) -, sem perspectiva de profissionalização. Entretanto, como esta autora coloca, quando as atividades musicais começavam a fazer parte de seus projetos futuros, a ansiedade paterna se evidenciava como uma preocupação com o futuro profissional de seus filhos.

Também nos depoimentos colhidos, é recorrente a pressão familiar e também da sociedade, que não consideram a profissão de músico uma escolha acertada, por não ser estável financeiramente. Assim relata o Sujeito 4: "Quando eu escolhi que eu ia continuar em música, com dois ou três anos de violino, meu pai não queria tanto, porque ele conhece o mercado de trabalho aqui na Paraíba. Ele dizia: 'Ah, não é tão bom'” (S4-E1, 4/4/2017).

A preocupação com o mercado de trabalho não é exclusiva dos familiares, mas também de alguns sujeitos entrevistados, que têm consciência de que o trabalho com música é incerto. Vários autores também tratam da precariedade do mercado de trabalho na área. Segnini (2011) discute como, no Brasil, apesar do "intenso crescimento do trabalho em música, enquanto campo econômico", ainda é um espaço de trabalho de caráter intermitente, na medida em que predomina a atuação sem vínculo empregatício, como autônomo, sendo os direitos trabalhistas uma realidade para poucos.

Nesta mesma direção, Coli (2008, p. 99) discute a precarização do trabalho do músico, apontando que, por não ganharem o suficiente, muitas vezes não conseguem dedicar tanto tempo como gostariam ao trabalho préescolhido, tendo, assim, que preencher sua agenda com outras atividades. É nesta medida, inclusive, que a procura pela Licenciatura em Música da UFPB tem aumentado, por permitir prestar concurso para redes públicas de educação básica, como uma alternativa para conseguir certa estabilidade que permita "viver de música". Por isso, a maioria dos sujeitos participantes do curso de licenciatura pretende conciliar a carreira de instrumentista com a de professor:

[...] depois que eu terminar [a licenciatura], eu pretendo fazer mestrado, pretendo fazer doutorado, porque eu, de fato, quero me aprofundar nesse universo e, além dos palcos, eu também quero ser professor de música (S12-E1, 29/3/17). 
Esses participantes que vêm da música popular buscam também, no ensino superior, uma maior qualificação musical, refletindo a necessidade crescente do músico popular, como indica Melo (2015, p. 9), de procurar os estudos formais para complementar ou ampliar seus conhecimentos: "Também pretendo fazer bacharelado em piano, mestrado em canto popular. É... para tudo isso agregar" (S7-E2, 4/11/2016).

Em relação aos entrevistados que possuem habilitação em instrumentos de orquestra ou piano, o principal ambiente de formação musical antes do ingresso na universidade foi o das igrejas, contrariando o nosso pressuposto de que seria, em sua maioria, o de escolas especializadas ou conservatórios. Por serem "espaços musicais inclusivos que não colocam pré-requisitos técnicos rigorosos", como mostra Travassos (1999, p. 133), as igrejas têm cumprido importante papel na formação musical:

Ela [a tia] foi me ensinando as primeiras notinhas [...] Eu lembro que eu peguei, eu já comecei a tocar a música que ela estava estudando. Eu lembro do hino que chamava "Vim para adorar-Te", aí foi quando eu decidi entrar na escola de música da igreja [...]. Foi exatamente nesse momento que eu, de fato, entrei no estudo da música (S1-E1, 26/9/2016).

Por sua vez, a maioria dos sujeitos que se dedicava ao canto ou aos instrumentos populares teve, no início dos seus estudos, experiências com a educação informal e não formal. Participavam de corais, ou adquiriam um violão e aprendiam a tocar em um processo de autoaprendizagem (Corrêa, 2000), ou observavam colegas e familiares. Também foram mencionadas outras práticas que permitiram traçar um paralelo com as cinco principais características da aprendizagem musical informal, segundo Green (2012, p. 67): escolha de um repertório familiar, a prática de "tirar músicas de ouvido", aprendizagem em grupo, assimilação de conhecimento de forma pessoal e articulação entre apreciação, execução, improvisação e composição.

Todas as bandas que eu participei foram grandes escolas, sabe? Os colegas de banda, aquela conversa, só o fato, mesmo que não tenha ninguém muito experiente, mas só o fato de estar ali em um grupo tentando fazer música, tentando montar uma apresentação, é um exercício fora de série [...], porque todo mundo está aprendendo junto, crescendo junto profissionalmente e tudo mais (S9-E1, 27/9/2016).

Vemos, portanto, que os diferentes percursos individuais passam por diversos contextos socioculturais, nos quais são estabelecidas as relações pessoais e subjetivas com a música.

\section{SIGNIFICAÇÕES PESSOAIS DA RELAÇÃO COM A MÚSICA}

Num segundo momento da análise, tomamos como referência a Logoteoria de Frankl, para a qual os sentidos e os valores movem o ser 
humano a tomar uma atitude diante de uma dada circunstância. Uma vez que ele não pode ser "visto como um sistema fechado de estímulos ou reflexos" (Miguez, 2014, p. 83), interpretamos, nos depoimentos coletados, o modo como os entrevistados adotaram diferentes significações para a música em suas histórias de vida.

Nos seus relatos, foi possivel perceber que muitos conceitos da Logoteoria estavam presentes, como o conceito de liberdade de vontade. Sendo o homem um ser que decide, e suas opções configuram o seu destino, mesmo diante de pressões do meio ambiente (Miguez, 2014, p. 39), os sujeitos participantes, em algum momento de suas vidas, tiveram que fazer uma escolha consciente e autônoma. Decidir-se por fazer música, persistir em sua prática, aprimorando-a para sua formação e atuação profissional, exigiu de cada um coragem - tanto pessoal quanto social - de admitir que a relação com a música assumia em suas vidas uma significação maior:

No terceiro ano do ensino médio eu decidi que não queria mais fazer o concurso para o Exército. Eu cresci com essa mentalidade que o meu pai impôs na minha mente [...]. E chegou um momento da minha vida, quando eu desenvolvi um senso mais crítico, que eu disse: "Não, eu não quero para minha vida profissional um trabalho que vá me trazer frustração, que eu não vá fazer com prazer, com felicidade, né?[...]. Aî eu disse: "Não, não vou fazer isso" (S1-E1, 26/9/2016).

Para a Logoteoria, o homem possui a capacidade do autodistanciamento, que lhe permite se posicionar diante de uma circunstância, distanciando-se de sua própria situação, sem se diluir nela (Miguez, 2014, p. 39). Deste modo, para alguns entrevistados, a escolha pela música foi uma forma de escapar das determinações de seus ambientes socioculturais. Para o Sujeito 7, a música foi uma forma de evitar um destino comum para jovens de sua cidade do interior, que era casar e ter filhos cedo, não concluir os estudos e não crescer profissionalmente:

[...] eu acho que para a minha vida inteira eu trago a música como uma forma que Deus me deu como libertação, sabe? [...] Eu via essa vida que eu não queria para mim. [...] Tudo o que aconteceu na minha vida foi de certa forma só para me levar à música, sabe? Mesmo que eu tenha encontrado dificuldades [...]. Então, tudo isso volta a uma mesma coisa, ela me libertou de uma coisa que eu não queria viver, ela me deu novos caminhos [...] (S7-E2, 4/11/2016).

Outro conceito central da Logoteoria é a vontade de sentido, que motiva o homem a buscar nas situações as possibilidades e a certeza de dever cumprido. Segundo Frankl (2014, p. 124), “esse sentido é exclusivo e específico, uma vez que precisa e pode ser cumprido somente por aquela determinada pessoa". Assim, cada entrevistado estabelece uma relação 
subjetiva, única e diferente com a música, seja estudando, executando ou ensinando.

Como a vontade de sentido orienta o indivíduo a buscar um sentido a realizar, podemos perceber claramente essa vontade em depoimentos dos participantes:

Então, eu tinha cerca de um mês só para estudar para prova [de seleção para o curso técnico]. Aí eu comecei a me desesperar, estudava de madrugada, acordava às 4 horas da manhã para estudar, eu queria porque queria estudar música e era a única oportunidade que eu tinha (S7-E), $27 / 9 / 2016$, grifos nossos).

Acho que é uma questão de vocação. A gente é escolhido, então a gente tem força para fazer aquilo, né? Se você quer muito fazer uma coisa, ainda que o povo fale que não vai dar certo, pode até a sua família falar, mas, se você sente que aquilo é o que é para você fazer, você faz e faz bem feito. É isso que importa! (S6-E2, 15/5/2017).

Outro aspecto muito pessoal da vontade de sentido revelado nas entrevistas foi a relação com Deus, que remete ao conceito de suprassentido, um sentido último que excede e ultrapassa a capacidade intelectual finita do ser humano e transcende a lógica (Frankl, 2014, p. 142).

Para mim, não tem valor, significância se eu faço [música] aqui [na universidade] e não faço lá [na igreja]. [...] Então, se eu deixo de agradecer a Ele com o meu louvor, de adorá-lo com o meu louvor, então isso aqui não tem significado, não tem importância. Então está totalmente ligado! (S1-E2, $7 / 11 / 2016)$.

Assim, ter alguém para amar, uma obra a realizar ou uma atitude a tomar dá ao homem um sentido existencial, uma razão de viver. Quando falta esta razão, encontramos o que Frankl denomina de vazio existencial: a ausência da vontade de sentido, que se manifesta em tédio e na sensação de que a vida não faz sentido.

Fiz o curso inteiro [Direito], me formei [...], fiz vários concursos [...]. Comecei a trabalhar [...]. Não me identifiquei. Abandonei e fiquei nessa: "Não quero Direito, mas o que que eu vou fazer?". Às vezes que eu me lembrava do violino: "Se eu tivesse seguido a música? [...] E aí foi passando, [...] e eu em crise profissional. [...] Até que eu estava em uma depressão, comecei a fazer terapia, e aí a psicóloga disse: "Ah, por que você não faz algum curso aí de artes, alguma coisa do tipo?" (S3-E1,2/12/2016).

A realização do sentido de vida pode vir de valores criativos, vivenciais e atitudinais, ou seja, o sentido pode vir por meio de criações artísticas, dos 
relacionamentos e das experiências. Os valores criativos foram os mais evidentes nos relatos, através da criação e da expressão musical: "Tudo vale a pena quando ela [a música] está pronta, quando ela é apresentada, quando você está no palco" (S7-E1, 27/9/2016).

Os outros tipos de valores também se revelaram, em relação à capacidade de transformar uma dificuldade em uma realização. Críticas, conflitos familiares e dificuldades financeiras foram algumas adversidades enfrentadas pelos entrevistados:

Já sofri muito por causa disso, muito mesmo, mas também posso dizer que é uma das coisas que, se [a música] não for a coisa que me faz mais feliz, também é a coisa que está bem mais perto de me fazer feliz. Eu tive de sentimentos... ruins... não que a música tenha provocado, mas algumas pessoas provocaram através dela [...], [alguém] dizer, tipo: "Você não nasceu para isso. Você é desafinado. Você não dá para cantar música popular. Sua voz é muito erudita ou então não dá para você entrar no mundo erudito" (S7-E1, 27/9/2016).

Às vezes, eu não tinha estrutura emocional para aguentar certas coisas e minha família cobrava muito, era bem chato. Era uma preocupação diária: "Você tem que deixar essa vida", e eu não queria e ficava aquela briga constante. E chegou ao ponto e teve um tempo que eu desisti, fui estudar outra coisa. Depois de um ano, eu voltei e continuei com o clarinete (S8E1, 30/9/2016).

Entretanto, ao relatarem os obstáculos e como se sentiam em relação às conquistas que conseguiram a partir da música, os Sujeitos 7 e 8 expressaram claramente ter nela um sentido de vida: cada um desses momentos serviu para alcançar a música como um objetivo maior. Como indica Damásio (2010, p. 45), "o ser humano tem de ter uma meta em direção a um fim e um propósito refletido no porvir, para, então, não desistir da vida". Assim, para o Sujeito 7, a dificuldade "foi só um passo, sabe? Tipo, cada coisa que você faz até chegar em um determinado ponto é só um passo, é só sempre mais um passo" (S7-E2, 4/11/2016).

De acordo com Miguez (2014), estas três categorias de valores - criativos, vivenciais e atitudinais - podem servir de via para encontrar o sentido e seus possiveis desdobramentos no âmbito da educação:

Resumidamente, pode-se pensar nas seguintes prospectivas pedagógicas: educar para a criatividade, promovendo a experiência de "oferecer algo de si" ao mundo e ao outro; educar para a convivência, promovendo as mais variadas experiências de cooperação, solidariedade, ajuda mútua, além da sensibilização para perceber a relação entre o mundo do valor e da cultura. [...] pensar na gama de situações que possibilitam viver a capacidade de superação que gera crescimento para além de si próprio (Miguez, 2014, p. 225). 
Muitas vezes, no entanto, as relações com a música nos espaços institucionais podem ser até mesmo dolorosas, como foi o caso do Sujeito 5, que relatou sobre os primeiros ensaios em uma orquestra: "Os meus primeiros ensaios foram, assim, terriveis, terriveis assim de você voltar chorando para casa [...]” (S5-E1, 4/4/2017). Embora a pressão psicológica o tenha feito procurar ajuda profissional, pensar em desistir lhe causava mais dor do que ficar e enfrentar os desafios que a música e seu instrumento lhe impunham:

A primeira coisa que eu fiz foi procurar um psicólogo, de verdade, eu fiquei muito mal. Mal ao ponto de procurar um psicólogo. Meus pais também me incentivaram, né? [...] Ele [pai] falou assim: "[...] Realmente é isso [o problema com a orquestra]? Porque, se for isso, você faz o Enem de novo, presta para engenharia" [...]. Aí, quando ele falou isso, doeu mais! Doeu mais estar dentro da empresa de engenharia do que estar tocando na orquestra (S5-E2, 19/5/2017).

No entanto, Miguez (2014) argumenta que as relações entre professores e alunos deveriam minimizar as tensões, sem imposições que impedissem o encontro dos educandos com os valores existenciais:

A relação interpessoal educador-educando não é mero acessório, mas fundamental no processo educativo de mediar consciência e significado. Essa interação educativa deve renunciar a qualquer ação coercitiva; ao contrário, sua intervenção tem um "caráter apelativo", atuando sobre a vontade de sentido e a capacidade de autotranscendência (Miguez, 2014, p. 111).

Nesta direção, o relato do Sujeito 4 revela o papel que uma professora de violino teve em sua vida:

[...] o papel mais importante dela foi me fazer gostar do meu instrumento, porque a minha relação não era boa. Na verdade, [...] eu odiava o violino, e ela criou uma missão de me fazer gostar e, com a vida profissional dela e com o jeito dela, me fez olhar de forma diferente para o meu instrumento, para a vida que eu poderia ter com ele. Então, [...] apesar de ter trocado de professor, ainda tenho muito contato com ela, peço muitos conselhos, porque a gente sabe que não é fácil, mas ela teve, tem uma boa carreira a se seguir como modelo (S4$\mathrm{E} 2,15 / 5 / 2017)$.

Um importante aspecto do sentido de vida é a descoberta do sentido. Damásio (2010, p. 47-48) aponta que "o ser humano é um ente responsável e consciente e precisa realizar o sentido potencial de sua vida", sentido este que "deve ser descoberto no mundo, nas relações". Esse sentido é dinâmico, muda de acordo com o momento, pois não é fixo. Segundo Miguez (2014, p. 39), ele surge enquanto "possibilidade sobre uma realidade, sempre com a possibilidade de modificá-la na medida do possivel e quando necessário". 
Sendo assim, tanto o Sujeito 9 quanto o Sujeito 5 encontraram um sentido de vida relacionado à música, quando nos contam como se sentem em relação à decisão de estudar e trabalhar na área musical:

Eu tomei a decisão certa, porque eu terminei o curso de publicidade, eu já trabalhava com publicidade, mas não era algo que me realizava, sabe? [...] porque eu decidi ir por esse caminho [da música] e estão surgindo coisas que eu não conhecia e que, se eu não tivesse vindo por esse caminho, eu não ia descobrir. E são coisas que estão me fascinando, sabe? (S9-E2, 16/11/2016).

[...] piano me deixava essa dúvida no meio, harpa não! Quando eu toquei harpa, quando eu vi a harpa, eu falei: "Bom, é isso que eu quero fazer!". Estou feliz, estou legal, fiquei sem dúvidas. Com piano, não, eu poderia fazer tanto piano quanto engenharia, por exemplo. Não necessariamente que eu tivesse que ser um profissional, um pianista, mas com harpa, não, eu já me imaginava tocando etc. (S5-E2, 19/5/2017).

$\mathrm{Na}$ perspectiva de Frankl, podemos ainda observar a questão da autotranscendência, que significa "a capacidade do homem de sair de si mesmo e voltar-se para algo ou alguém que está além de si próprio" (Damásio, 2010 , p. 34), e também perceber a "qualidade pessoal do outro, aquilo que o constitui como único e irrepetivel” (Miguez, 2014, p. 75). Todos os entrevistados revelaram um desejo de, através da música, ajudar o próximo.

Como eu já sou professor, [...] então eu penso no cargo de gerir, de administração. [Penso em] conseguir, cada dia mais resgatar, proporcionar a esses jovens algo melhor. Essa é a minha única outra paixão, que eu descobri o lado social que eu tenho vontade de trabalhar (S2-E2, 7/11/2016).

Buscar um sentido de vida pressupõe, segundo Frank1, elaborar um projeto de vida que viabilize realizar aquilo que antecipadamente vislumbramos:

Eu pretendo ser professor na universidade, é uma meta minha a longo prazo [...]. É um dos segmentos que pretendo seguir, essa parte da musicoterapia e da musicalização [...]. Mas algo que eu nunca vou deixar, nunca vou me desligar, é essa questão de banda, de grupo, que eu gosto bastante, tocar, me apresentar (S9-E2, 16/11/2016).

Deste modo, como aponta Damásio (2010, p. 49), “elaborar um projeto é, por antecipação, fotografar determinadas atividades que serão realizadas no futuro, a posteriore". E diversas falas dos entrevistados evidenciam esse vínculo entre sentido e projetos de vida, sempre envolvendo diversas formas de se relacionar com a música. 


\section{CONSIDERAÇÕES FINAIS}

Ao longo de nossa análise, além das relações pessoais e subjetivas com a música, outras questões surgiram, como as vivências, os diferentes modos e ambientes socioculturais em que ocorreram práticas educativas, escolares ou não. Desta forma, buscamos interligar a dimensão subjetiva e os fatores sociais e culturais. Assim, acreditamos que esta pesquisa, ainda em andamento, poderá trazer contribuições para a área de educação musical, discutindo como diferentes contextos e formas de ensinar/aprender influem nas relações pessoais e subjetivas com a música.

As narrativas de diferentes histórias de vida musical nos levaram a algumas reflexões em relação à formação inicial dos sujeitos, aos ambientes de iniciação musical, às experiências de vida anteriores ao ambiente acadêmico e aos próprios estudos e práticas na universidade. Pudemos perceber que cada sujeito mantém uma relação única e pessoal com a música, o que dá a ela diferentes significações, por se tratar de questões subjetivas. Constatamos que os sujeitos entrevistados vêm, de múltiplas formas, realizando sentidos e propósitos através de suas atividades musicais, sejam de performance, que a maioria considera essencial, sejam de ensino e criação. Cada um, ao seu modo, está realizando a dificil tarefa de escrever a sua própria história, que tem na música um papel central.

A partir daí, então, é possível questionar como as práticas de educação musical podem lidar com essas diferentes significações que os alunos estabelecem com a música, inclusive ajudando a repensar padrões de ensino ainda vigentes. Algumas práticas, concepções e "mitos" vinculados ao ensino tradicional de música ${ }^{8}$ - especialmente a ênfase no virtuosismo técnico e a crença no talento inato - desconsideram a importância das relações pessoais e subjetivas com a música, o esforço que muitos sujeitos fazem para estar em um curso superior de música e o sentido da música para suas vidas.

Assim, encerramos não com uma conclusão, mas com um questionamento: Como as práticas de educação musical podem lidar com essas diferentes significações que os alunos estabelecem com a música - e respeitá-las?

\section{REFERENCIAS}

ALMEIDA, Cristiane Maria Galdino de. Educação musical não-formal e atuação profissional. Revista da ABEM, Porto Alegre, n. 13, p. 49-56, set. 2005.

AQUINO, Sandra Kalina Martins Cabral de. Os sentidos da performance e da docência à luz da logoteoria: um estudo com professores de instrumento em

\footnotetext{
${ }^{8}$ A respeito, ver Burnard (2012, caps. 1 e 2).
} 
duas universidades do Nordeste. 2017. Tese (Doutorado) - Programa de PósGraduação em Música, Universidade Federal da Paraíba, João Pessoa, 2017.

ARAÚJO, Rosane Cardoso de. Motivação para prática e aprendizagem da música. In: ARAÚJO, Rosane Cardoso de; RAMOS, Danilo (Orgs.). Estudos sobre motivação e emoção em cognição musical. Curitiba: Ed. UFPR, 2015. p. 45-58.

ARAÚJO, Rosane Cardoso de; RAMOS, Danilo (Orgs.). Estudos sobre motivação e emoção em cognição musical. Curitiba: Ed. UFPR, 2015.

BURNARD, Pamela. Musical creativities in practice. Oxford (UK): Oxford University Press, 2012.

COLI, Juliana Marília. Descendência tropical de Mozart: trabalho e precarização no campo musical. ArtCultura, Uberlândia, v.10, n.11, p. 89102, jul./dez. 2008.

CORREAA, Marcos. Violão sem professor. um estudo sobre processos de autoaprendizagem com adolescentes. 2000. 191 f. Dissertação (Mestrado) Programa de Pós-Graduação em Música, Universidade Federal do Rio Grande do Sul, Porto Alegre, 2000.

COX, Gordon; CRICKMORE, Leon; PLUMMERIDGE, Charles; SERGEANT, Desmond. SEMPRE: Forty years on. Psychology of Music. v. 40, n. 5, p. 523538, 2012.

DAMÁSIO, Bruno F.; SILVA, Joilson P. da; AQUINO, Thiago A. Avellar de (Orgs.). Logoterapia e educação. São Paulo: Paulus, 2010.

DORING, Katharina. "A música começa na pessoa”: memória e identidade musical subjetiva. In: SEMINÁRIO NACIONAL DE PSICOLOGIA DA MÚSICA E EDUCAÇÃO MUSICAL, 1., Feira de Santana, 2016. Anais... Disponível em: <https://goo.gl/gngMfF>. Acesso em: 2 set. 2017.

DOURADO et. al. Fundamentos antropológicos da logoterapia e análise existencial. In: DAMÁSIO, Bruno F.; SILVA, Joilson P. da; AQUINO, Thiago A. Avellar de (Orgs.). Logoterapia e educação. São Paulo: Paulus, 2010. p. 13-52.

FLICK, Uwe. Uma introdução à pesquisa qualitativa. 2. ed. Porto Alegre: Bookman, 2004.

FRANKL, Viktor E. O que não está escrito nos meus livros: memórias. São Paulo: É realizações, 2010.

FRANKL, Viktor E. A vontade de sentido: fundamentos e aplicações da logoterapia. 2. ed. São Paulo: Paulus, 2013.

FRANKL, Viktor E. Em busca de sentido: um psicólogo no campo de concentração. 36. ed. Petrópolis: Vozes, 2014. 
GOMES, Celson. Educação musical na família: as lógicas do invisivel. Revista da Abem, Londrina, v. 19, n. 25, p. 30-40, jan./jun. 2011.

GREEN, Lucy. Ensino da música popular em si, para si e para "outra" música: uma pesquisa atual em sala de aula. Revista da Abem, Londrina, v. 20, n. 28, p. 61-80, 2012.

ILARI, Beatriz (Org.). Em busca da mente musical: ensaios sobre os processos cognitivos em música - da percepção à produção. Curitiba: Editora UFPR, 2006.

ILARI, Beatriz; ARAÚJO, Rosane Cardoso de (Orgs.). Mentes em música. Curitiba: DEARTES/UFPR, 2009.

KLEBER, Magali. A prática de educação musical em ONGS: dois estudos de caso no contexto urbano brasileiro. Curitiba: Appris, 2014.

MAGALHÃES, Luiz César Marques. A interface música e psicologia: uma perspectiva histórico-analítica. Revista Música, São Paulo, v. 15, n. 1, p. 127-146, 2016.

MELO, Bruno Torres Araújo de. Os efeitos de estudos formais associados ao recurso didático da gravação na prática de bateristas populares. 2015. $201 \mathrm{f}$. Dissertação (Mestrado) - Programa de Pós-Graduação em Música, Universidade Federal da Paraíba, João Pessoa, 2015.

MIGUEZ, Eloisa Marques. Educação em busca de sentido: pedagogia inspirada em Viktor Frankl. São Paulo: Paulus, 2014.

PENNA, Maura. Música(s) e seu ensino. 2. ed. rev. ampl. 3. reimpr. Porto Alegre: Sulina, 2015.

QUEIROZ, Andrea Matias. Experiências formativas em música na construção dos projetos de vida dos jovens: um estudo a partir de entrevistas narrativas. Revista Brasileira de Pesquisa (Auto)Biográfica, Salvador, v. 2, n. 5, p. 470-482, maio/ago. 2017.

SEGNINI, Liliana Rolfsen Petrilli. À procura do trabalho intermitente no campo da música. Estudos de Sociologia, Araraquara, v. 16, n. 30, p. 177196, 2011.

TRAVASSOS, Elizabeth. Redesenhando as fronteiras do gosto: estudantes de música e diversidade musical. Horizontes Antropológicos, Porto Alegre, ano 5, n. 11, p. 119-144, out. 1999.

VIEIRA, Lia Braga. A escolarização do ensino de música. Pro-posições, Campinas, v. 15, n. 2 (44), p. 141-150, maio/ago. 2004.

WILLE, Regiana Blank. Educação musical formal, não formal ou informal: um estudo sobre processos de ensino e aprendizagem musical de adolescentes. Revista da ABEM, Porto Alegre, n. 13, p. 39-48, set. 2005. 
Maura Penna é professora associada, atuando na Licenciatura em Música e no Programa de Pós-Graduação em Música da Universidade Federal da Paraíba / UFPB.

Ana Luiza Pinto é aluna da Licenciatura em Música da UFPB; bolsista de Iniciação Científica (PIBIC/CANPQ/UFPB). Coordenadora do Grupo de Pesquisa Música, Cultura e Educação.

Susie Santos é aluna da Licenciatura em Música da UFPB; bolsista de Iniciação Científica (PIBIC/CANPQ/UFPB). 